\title{
Antiplasmodial activity against resistant strains, toxicity and effect on mouse liver enzymes of extracts of Terminalia species found in Southwest Cameroon
}

\author{
Moses Njutain Ngemenya ${ }^{1,2^{*}}$, Grace Ntube Abwenzoh ${ }^{1}$, Denis Zofou ${ }^{1}$, Thierry Roland Kang ${ }^{1}$, James A. \\ $\mathrm{Mbah}^{3}$ (1) \\ ${ }^{1}$ Department of Biochemistry and Molecular Biology, Faculty of Science, University of Buea, P.O. Box 63 Buea, South West Region, Cameroon \\ ${ }^{2}$ Department of Medical Laboratory Sciences, Faculty of Health Sciences, University of Buea, P.O. Box 63 Buea, South West Region, Cameroon \\ 3Department of Chemistry, Faculty of Science, University of Buea, P.O. Box 63, Buea, Cameroon
}

\section{A R T I C L E I N F O}

Article Type:

Original Article

Article History:

Received: 30 December 2019

Accepted: 31 March 2020

\section{Keywords:}

Terminalia

Antiplasmodial activity

Resistance

Medicinal plants

Toxicity

Liver enzymes

\begin{abstract}
A B S T R A C T
Introduction: Terminalia species have the potential to be exploited in phytomedicine based on their several pharmacological properties including antiplasmodial activity. However, there is need for more data on their antiplasmodial activity and toxicity. This study evaluated the antiplasmodial activities of Terminalia catappa and Terminalia superba found in the coastal area of Cameroon on resistant strains of Plasmodium falciparum not previously tested, and their toxicity.

Methods: Three leaf extracts of each plant prepared separately using three organic solvents were screened in vitro on 3 strains of $P$. falciparum: chloroquine-sensitive 3D7, chloroquine-resistant Dd2 and multi-drug resistant W2mef using the parasite growth inhibition assay. Antiplasmodial activity was assessed using fluorescence microscopy and the parasite lactate dehydrogenase assay. Cytotoxicity of active extracts was assessed on LLC-MK2 monkey kidney epithelial cells and acute toxicity including effect on some liver enzymes in BALB/c mice.

Results: The methanol extracts of both plants showed the highest antiplasmodial activity (IC ${ }_{50}$ between $5.03-9.76 \mu \mathrm{g} / \mathrm{mL}$ ) on the three parasite strains. The methanol extracts showed high selectivity for parasites with selectivity index values ranging from 40 to 80 indicating very low risk of toxicity. There was no mortality or adverse effect and no significant effect on the liver enzymes, alanine aminotransferase $(P=0.506)$ and aspartate aminotransferase $(P=0.243)$.

Conclusion: The antiplasmodial activity, high selectivity and no adverse effects for T. catappa and T. superba demonstrate the potential for use of these plants in traditional treatment of malaria, further development into a phytomedicine against malaria and as source of new antimalarial lead.
\end{abstract}

Implication for health policy/practice/research/medical education:

This study confirms the high antiplasmodial activity and safety of T. catappa and T. superba leaves. This supports their use in traditional treatment of malaria, further development into an antimalarial phytomedicine and search for antimalarial lead from their secondary metabolites.

Please cite this paper as: Ngemenya MN, Abwenzoh GN, Zofou D, Kang TR, Mbah JA. Antiplasmodial activity against resistant strains, toxicity and effect on mouse liver enzymes of extracts of Terminalia species. J Herbmed Pharmacol. 2021;10(1):132-138. doi: $10.34172 /$ jhp.2021.14.

\section{Introduction}

The malaria burden remains high as parasite resistance continues to increase. According to the World Health Organization, there is clinical evidence of resistance to the artemisinins which are presently the first line treatment for malaria. This resistance presents as delayed parasite clearance following artesunate monotherapy or artemisinin-based combination therapy, for which there is a molecular marker as experimental evidence $(1,2)$. As at present, only one vaccine with limited efficacy has been approved for phase III trial in humans (3). Hence, chemotherapy remains the main tool in the fight against 
malaria. In the face of emerging and increasing resistance, the search for new efficacious and safe antimalarials is urgent. The approaches presently used to discover new antimalarials include combination therapy, chemical modification of antimalarial molecules in use, medicinal chemistry and screening of natural products mainly of plant origin among others $(4,5)$.

Terminalia species belonging to the family Combretaceae, and particularly Terminalia catappa and T. superba which both grow in the tropic areas, are well described in the literature. The uses of T. catappa in traditional medicine are well documented particularly in the Asian continent with scanty information on its traditional use in Africa and South America. Experimental studies of T. catappa have reported a wide range of pharmacological activities including antidiabetic, anti-inflammatory, antitumour, antibacterial, antifungal, antiparasitic properties among several others (6). The leaves of T. catappa are most frequently used in traditional medicine. Some studies have reported antiplasmodial activity of aqueous and organic solvent extracts of the leaves against patient parasites (7), and characterised laboratory strains of Plasmodium falciparum, both chloroquine sensitive (NF54) and resistant (K1). These studies also tested for cytotoxicity on mammalian cell lines (L6 and Madin-Darby Bovine Kidney cells) and recorded good selectivity for the parasite $(8,9)$. T. superba has also been investigated and antifungal, antibacterial and antihypertensive activities reported for various parts of the species $(10,11)$. The antiplasmodial activity of $T$. superba found in central Cameroon was reported against chloroquine-resistant $P f I N D O$ and sensitive Pf3D7 strains of $P$. falciparum, respectively (12). Although T. catappa has been reported to be hepatoprotective (13), the acute toxicity and effect in the liver have not been extensively investigated. Hence, there is a need for more data on the antiplasmodial property and toxicity of these important medicinal plants to support their exploitation in the development of a phytomedicine for use in the treatment of resistant malaria. Hence, this study was designed to investigate the antiplasmodial activities of the extracts of T. catappa and T. superba found in the coastal area of Southwest Cameroon against $P$. falciparum chloroquinesensitive 3D7, chloroquine-resistant $\mathrm{Dd} 2$ and multidrug resistant W2mef. Cytotoxicity of active extracts was assessed on LLC-MK2 monkey kidney epithelial cells and acute toxicity including effect in the liver were also investigated in mice.

\section{Materials and Methods}

Collection of plants and preparation of crude extracts The leaves of T. catappa and T. superba were collected at the Limbe Botanic Garden, Limbe Sub Division, and Dibanda village, Buea Sub Division respectively, locations close to the Atlantic Ocean, in the South West region of Cameroon. The leaves were identified by $\mathrm{Mr}$. Peter Njimba, a botanist at the Limbe Biodiversity and Conservation Centre, and the specimens were deposited in the herbarium of this centre with voucher numbers SCA2068 and SCA2073, respectively. The leaves were air-dried, ground to fine powder and 100 grams of each powder was macerated separately for 72 hours in $1 \mathrm{~L}$ of each of hexane (Hex), methylene chloride $\left(\mathrm{CH}_{2} \mathrm{Cl}_{2}\right)$ and methanol $(\mathrm{MeOH})$. The mixtures were filtered using Whatman filter paper No. 1 (pore size $60 \mu \mathrm{A}^{\circ}$ ) and the filtrates concentrated under reduced pressure by rotary evaporation (BUCHI Rotavapor RE-111, Switzerland) at the following temperatures: $60 \pm 5^{\circ} \mathrm{C}$ for $\mathrm{Hex}, 70 \pm 5^{\circ} \mathrm{C}$ for $\mathrm{CH}_{2} \mathrm{Cl}_{2}$ and $45 \pm 5^{\circ} \mathrm{C}$ for $\mathrm{MeOH}$. The extracts were then air-dried overnight to remove residual extraction solvent and the extracts retrieved from the evaporation flask into vials and stored at $-20^{\circ} \mathrm{C}$ until tested.

Preparation of stock solutions of crude extracts Five milligrams ( $5 \mathrm{mg}$ ) of each crude extract was dissolved in $100-200 \mu \mathrm{L}$ of dimethylsulphoxide (DMSO), kept overnight at $37^{\circ} \mathrm{C}$ overnight to dissolve completely and gentamycin-free incomplete culture medium was added giving a final concentration of $1 \mathrm{mg} / \mathrm{mL}$. Solutions of artemether $(5 \mu \mathrm{g} / \mathrm{mL})$ and quinine $(10 \mu \mathrm{g} / \mathrm{mL})$ were prepared similarly. The stock solutions were mixed thoroughly by vortexing, sterile filtered using a $0.22 \mu \mathrm{m}$ pore syringe filter (Corning, USA), sealed with parafilm and stored at $-20^{\circ} \mathrm{C}$ until when used.

\section{Plasmodium parasite culture}

Three P. falciparum strains, chloroquine-sensitive 3D7 (MRA-102), chloroquine-resistant Dd2 (MRA-150) and multi-drug resistant W2mef (MRA-615) were obtained from BEI-Resources, Manassas, VA, USA. The parasites were stored, thawed and maintained in continuous culture by the candle jar technique (14) as described with some modifications (15). The culture consisted of $4 \%$ hematocrit suspension of human O+ erythrocytes in RPMI-1640 medium supplemented with gentamycin solution at 0.01 $\mathrm{mg} / \mathrm{mL}, 25 \mathrm{mM}$ Hepes buffer, $25 \mathrm{mM} \mathrm{NaHCO}_{3}$ and 5 g/L Albumax II (Gibco; Invitrogen, USA). Cultures were incubated at $37^{\circ} \mathrm{C}$ with a gas mixture containing $5 \% \mathrm{CO}_{2}$.

In vitro growth inhibition assays

A primary screen was initially performed to identify substances with considerable activity i.e. $>50 \%$ inhibition of parasite growth. This was followed by a secondary screen to determine the $\mathrm{IC}_{50} \mathrm{~s}$ of active extracts. All assays were performed in a 96 well culture plate (Corning, USA), incubated under the same conditions as the parasite cultures.

Primary screen of crude extracts

Each crude extract was tested at $100 \mu \mathrm{g} / \mathrm{mL}$ in triplicate. A 
volume of $100 \mu \mathrm{L}$ of the test solutions was added into the required wells followed by $100 \mu \mathrm{L}$ of $1 \%$ parasitized blood. Positive $(5 \mu \mathrm{g} / \mathrm{mL}$ artemether) and negative controls (no drug) wells were included. The plate was incubated under culture conditions as above for 48 hours. Then, antiplasmodial activity was assessed by fluorescence microscopy using acridine orange stain at $\times 40$ objective under oil immersion (15). The number of infected erythrocytes (Ei) were counted in 20 fields per well with a uniform monolayer of cells (approximately 1500 cells per field) and the percentage parasitaemia was calculated using the formula:

$\%$ Parasitaemia $=[(\Sigma \mathrm{Ei} \div 30,000) \times 100]$ per well

$\%$ Inhibition per concentration for triplicate wells = $\frac{\text { Mean \% parasitaemia in control wells - Mean \% parasitaemia in test wells }}{\text { Mean } \% \text { parasitaemia in control wells }} \times 100$

\section{Secondary screen of crude extracts}

A semi-automated method as previously described was used with some modifications (16). Each crude extract was tested in triplicate wells by a two-fold serial dilution to obtain concentrations ranging from 1.5625 to $100 \mu \mathrm{g} / \mathrm{mL}$ and incubated for 48 hours. The wells were checked for adequate growth of parasite in the control and inhibition of growth in the test using fluorescence microscopy and the plate was then stored at $-20^{\circ} \mathrm{C}$.

Parasite growth quantification by lactate dehydrogenase assay

Plates frozen at $-20^{\circ} \mathrm{C}$ were subjected to 3 freeze-thaw cycles to haemolyze the red blood cells. One hundred microlitres $(100 \mu \mathrm{L})$ of Malstat reagent $(400 \mu \mathrm{L}$ of triton $\mathrm{X}-100,4 \mathrm{~g}$ of L-lactate, $1.32 \mathrm{~g}$ of Tris buffer, $22 \mathrm{mg}$ of APAD in $200 \mathrm{~mL}$ of deionized water, $\mathrm{pH}$ adjusted to 9) was added to each well of a 96 well microtitre plate and $20 \mu \mathrm{L}$ of culture was taken from each well and added to corresponding wells of the Malstat plate. Finally, $25 \mu \mathrm{L}$ of NBT/PES solution (160 mg of nitroblue tetrazolium salt and $8 \mathrm{mg}$ of phenazine ethosulfate in $100 \mathrm{~mL}$ of deionised water) was then added to each well, initiating the reaction. The plates were then incubated for an hour in the dark and the optical density was measured at $650 \mathrm{~nm}$ with the aid of a plate reader (Emax-Molecular Devices Corporation, California, USA) (15).

\section{Cytotoxicity test}

The cytotoxicity of active extracts was investigated on LLC-MK2 monkey kidney epithelial cells (ATCC, USA) as previously described (17). The cells were distributed in a 96 well plate, $1 \times 10^{4}$ cells in $100 \mu \mathrm{L}$ culture medium per well and grown for 24 hours to become confluent and attached to bottom of wells. The medium $(100 \mu \mathrm{L})$ was replaced with fresh medium. A volume of $100 \mu \mathrm{L}$ of crude extract at $1000 \mu \mathrm{g} / \mathrm{mL}$ was added in duplicate to the highest concentration wells and serially diluted twofold giving a final concentration range of 7.8 to $500 \mu \mathrm{g} / \mathrm{mL}$. The cells in wells without test substances served as the negative control. The plates were incubated for 72 hours at $37^{\circ} \mathrm{C}$ in $5 \% \mathrm{CO}_{2}$, cell concentration and viability were assessed using microscopy by counting the dead cells which appeared dark and deformed. This experiment was done twice.

Acute oral toxicity and effect on liver enzymes

Ethical approval was obtained from the Institutional Animal Care and Use Committee, University of Buea (UBIACUC N ${ }^{O}$ 013/2019). The methanol extract of T. catappa was investigated following guidelines of the Organization for Economic Cooperation and Development version 423 (18), as described in a previous work (19) using five nine weeks old BALB/c mice. Briefly, after administration of $2000 \mathrm{mg} / \mathrm{kg}$ body weight of extract (in 2\% DMSO) in one weighed mouse fasted overnight did not cause death, the rest of the mice were also fasted and the same dose administered. The animals were observed for gross changes such as loss of appetite, piloerection, lacrimation, tremors, convulsions, salivation, diarrhoea, mortality and other adverse signs for 14 days. At day 14, the animals were fasted over-night and then anesthetized with ketamine/ xylazine $(90 / 10 \mathrm{mg} / \mathrm{kg})$. Blood was collected into dry Eppendorf tubes by retro-orbital bleeding, allowed for 30 minutes to coagulate and centrifuged at $2200 \mathrm{rpm}$ for 15 minutes. The activities of alanine aminotransferase (ALT) and aspartate aminotransferase (AST) were measured in the serum using commercial test kits (Biorex Diagnostics, United Kingdom) following manufacturer's instructions.

\section{Statistical Analysis}

Data from $p L D H$ : Experiments were done in triplicate. Optical density (OD) values from control and test wells were corrected for background by subtracting OD values from blank wells containing non parasitized red blood cells (4\% suspension). The OD values obtained were used to determine the $\mathrm{IC}_{50}$ and $\mathrm{IC}_{95}$ values of crude extracts using the software HN-NonLin V1.1 (20) and IC Estimator Run Regression version 1.1, an online calculator of IC values. The IC values per concentration were expressed as mean IC \pm S.D using Microsoft excel 2007.

Cytotoxicity was calculated as the mean of the four $\mathrm{CC}_{50}$ values. The selectivity index (SI) was calculated using the formula: $\mathrm{SI}=\mathrm{CC}_{50}$ on LLC-MK2 cells $\div \mathrm{IC}_{50}$ on $P$. falciparum.

The activities of the serum enzymes were calculated as prescribed by the manufacturer. The activities of the control and test groups of mice were compared using unpaired t-test and statistical significance taken at $P<$ 0.05 .

\section{Results}

Yield and activity of crude extracts

Following the primary screen, the highest extraction 
yields were obtained with methanol for both plants (Table 1). At $100 \mu \mathrm{g} / \mathrm{mL}$, four of the six crude extracts i.e. the methylene chloride and methanol extracts of both plants showed greater than $50 \%$ inhibition of parasite growth. The methanol extracts showed the highest (71 to $81 \%$ ) inhibition of the two parasite strains tested (3D7 and W2mef), followed by the methylene chloride extracts (50 to $61 \%$ ), while the hexane extracts showed the lowest inhibition (21 to $38 \%$ ), as shown on Table 1 . The secondary screen gave the $\mathrm{IC}_{50}$ values shown on Table 2 for the four extracts with greater than $50 \%$ inhibition in the primary screen. The $\mathrm{IC}_{50}$ values ranged from 5.51 to $31.062 \mu \mathrm{g} / \mathrm{mL}$ against $3 \mathrm{D} 7$ and 5.03 to $64 \mu \mathrm{g} / \mathrm{mL}$ against W2mef. The $\mathrm{IC}_{50}$ values generally indicate that the extracts were active on all the three parasite strains. The methanol extracts of both plants $\left(\mathrm{TC}_{\mathrm{MeOH}}\right.$ and $\left.\mathrm{TS}_{\mathrm{MeOH}}\right)$ showed higher antiplasmodial activity while $\mathrm{TS}_{\mathrm{MC}}$ was the least active. The $\mathrm{IC}_{95}$ ranged from 77 to 95 and was consistently higher than the $\mathrm{IC}_{50}$ for each parasite strain.

Cytotoxicity and acute toxicity of active substances The two most active crude extracts $\left(\mathrm{TC}_{\mathrm{MeOH}}\right.$ and $\left.\mathrm{TS}_{\mathrm{MeOH}}\right)$ were not cytotoxic on LLC monkey kidney cells based on published criteria (21) whereby a substance with a $\mathrm{CC}_{50}$ $>30 \mu \mathrm{g} / \mathrm{mL}$ and $\mathrm{SI}>10$ is considered non-cytotoxic. The two crude extracts demonstrated very high selectivity for the parasite as seen from the very high $\mathrm{CC}_{50}$ values on the LLC monkey kidney cells and the high SI values for all three parasite strains (Table 3 ). In the acute toxicity test at $2000 \mathrm{mg} / \mathrm{kg}$ body weight, no mortality was recorded after 14 days with no adverse effect. Body weight increased in both the control and test groups of mice during the test period with no significant difference between the two groups.

For the effect on the liver enzymes, ALT levels were higher in the test group of mice than the control while AST was lower in the test group after 14 days giving AST: ALT ratios of 0.82 and 0.38 for the control and test groups, respectively. There was no significant difference in the activity of the liver enzymes, ALT $(P=0.506)$ and AST $(P$ $=0.243$ ) between the control and test groups (Figure 1).

\section{Discussion}

With growing scientific evidence of emergence of parasite strains with reduced sensitivity to the artemisinins, which are the last class of efficacious drugs approved for the treatment of clinical malaria $(1,2)$, there is a constant need for new safe and highly efficacious antimalarials to counter resistance in clinical malaria. Selection of these plant species was based on documented ethnopharmacology.

Table 1. Extraction yield of crude extracts of $T$. catappa and $T$. Superba leaves and antiplasmodial activity in primary screen

\begin{tabular}{|c|c|c|c|c|}
\hline \multirow{2}{*}{ Plant } & \multirow{2}{*}{ Extract code } & \multirow{2}{*}{ Percentage yield (w/w) } & \multicolumn{2}{|c|}{ Antiplasmodial activity at $100 \mu \mathrm{g} / \mathrm{mL}$ (\% inhibition) } \\
\hline & & & 3D7 & W2mef \\
\hline \multirow{3}{*}{$\begin{array}{l}\text { Terminalia } \\
\text { catappa }\end{array}$} & $\mathrm{TC}_{\mathrm{MeOH}}$ & $7.2 \%$ & $81.01 \%$ & $74.6 \%$ \\
\hline & $\mathrm{TC}_{\mathrm{MC}}$ & $4.4 \%$ & $52.15 \%$ & $53.0 \%$ \\
\hline & $\mathrm{TC}_{\text {Hex }}$ & $2.6 \%$ & $38.23 \%$ & $36.1 \%$ \\
\hline \multirow{4}{*}{$\begin{array}{l}\text { Terminalia } \\
\text { superba }\end{array}$} & $\mathrm{TS}_{\mathrm{MeOH}}$ & $11.2 \%$ & $76.46 \%$ & $71.3 \%$ \\
\hline & $\mathrm{TS}_{\mathrm{MC}}$ & $4.6 \%$ & $50.38 \%$ & $61.4 \%$ \\
\hline & $\mathrm{TS}_{\mathrm{Hex}}$ & $5.5 \%$ & $27.98 \%$ & $21.1 \%$ \\
\hline & Artemether* $(2.5 \mu \mathrm{g} / \mathrm{mL})$ & NA & $96.8 \%$ & $92.14 \%$ \\
\hline
\end{tabular}

$\mathrm{TC}_{\mathrm{MeOH}}, \mathrm{TC}_{\mathrm{MC}}$ and $\mathrm{TC}_{\mathrm{Hex}}$ : methanol, methylene chloride and hexane extracts of $T$. catappa, respectively. $\mathrm{TS}_{\mathrm{MeOH}}, \mathrm{TS}_{\mathrm{MC}}$ and $\mathrm{TS}_{\mathrm{Hex}}:$ methanol, methylene chloride and hexane extracts of $T$. superba, respectively. ${ }^{*}$ Artemether is positive control. P. falciparum 3D7 is chloroquine-sensitive and W2mef is a multi-drug resistant strain. NA: not applicable.

Table 2. Antiplasmodial activity of crude extracts of $T$. catappa and $T$. superba leaves in secondary screen

\begin{tabular}{|c|c|c|c|c|c|c|}
\hline \multirow{3}{*}{ Extract code } & \multicolumn{6}{|c|}{ Activity } \\
\hline & \multicolumn{2}{|c|}{ 3D7 } & \multicolumn{2}{|c|}{ W2mef } & \multicolumn{2}{|c|}{ Dd2 } \\
\hline & $\mathrm{IC}_{50}(\mu \mathrm{g} / \mathrm{mL})$ & $\mathrm{IC}_{95}(\mu \mathrm{g} / \mathrm{mL})$ & $\mathrm{IC}_{50}(\mu \mathrm{g} / \mathrm{mL})$ & $\mathrm{IC}_{95}(\mu \mathrm{g} / \mathrm{mL})$ & $\mathrm{IC}_{50}(\mu \mathrm{g} / \mathrm{mL})$ & $\mathrm{IC}_{95}(\mu \mathrm{g} / \mathrm{mL})$ \\
\hline $\mathrm{TC}_{\mathrm{MeOH}}$ & $5.51 \pm 0.6$ & $77.14 \pm 7.9$ & $5.03 \pm 0.1$ & ND & $9.498 \pm 0.6$ & $81.63 \pm 7.9$ \\
\hline $\mathrm{TC}_{\mathrm{MC}}$ & $29.05 \pm 5.8$ & $91.85 \pm 2.3$ & $19.91 \pm 0.7$ & ND & ND & ND \\
\hline $\mathrm{TS}_{\mathrm{MeOH}}$ & $6.16 \pm 0.03$ & $80.71 \pm 5.1$ & $7.014 \pm 0.1$ & ND & $9.769 \pm 1.4$ & $80.70 \pm 5.1$ \\
\hline $\mathrm{TS}_{\mathrm{MC}}$ & $31.06 \pm 8.0$ & $95.06 \pm 2.3$ & 64.00 & ND & ND & ND \\
\hline Art & $0.05 \pm 0$ & $0.05 \pm 0$ & 0.020 & 0.062 & 0.039 & 0.059 \\
\hline
\end{tabular}

P. falciparum strains: 3D7 chloroquine-sensitive, Dd2 chloroquine-resistant, and W2mef multi-drug resistant. Art $=$ arthemeter. Extract codes are defined in Table 1. Classification of activity of extracts: $I C_{50}<5 \mu \mathrm{g} / \mathrm{mL}=$ Highly active, $5<\mathrm{IC} \mathrm{F}_{50} \leq 10 \mu \mathrm{g} / \mathrm{mL}=\mathrm{active}, 10<\mathrm{IC}{ }_{50} \leq 25 \mu \mathrm{g} / \mathrm{mL}=\mathrm{moderately}$ active, $25 \mu \mathrm{g} / \mathrm{mL}<I C_{50} \leq 50 \mu \mathrm{g} / \mathrm{mL}=$ weakly active and $I C_{50}^{50}>50 \mu \mathrm{g} / \mathrm{mL}=$ inactive (16). ${ }^{*} \mathrm{ND}$ : Not determined. 
Table 3. $\mathrm{IC}_{50} \mathrm{~s}$, cytotoxicity and selectivity indices of methanol extracts of Terminalia catappa and Terminalia superba

\begin{tabular}{|c|c|c|c|c|c|c|}
\hline \multirow{2}{*}{ Compound code } & \multicolumn{2}{|l|}{$\mathrm{IC}_{50}(\mu \mathrm{g} / \mathrm{mL})$} & \multirow{2}{*}{$\begin{array}{l}\mathrm{CC}_{50}(\mu \mathrm{g} / \mathrm{mL}) \\
\text { LLC-MK2 cells }\end{array}$} & \multicolumn{3}{|c|}{ SI values } \\
\hline & 3D7 & Dd2 & & 3D7 & Dd2 & W2mef \\
\hline $\mathrm{TC}_{\mathrm{MeOH}}$ & $5.51 \pm 0.6^{a}$ & $9.498 \pm 0.6^{a}$ & 375 & 68.058 & 39.48 & 74.552 \\
\hline $\mathrm{TS}_{\mathrm{MeOH}}$ & $6.16 \pm 0.03^{\mathrm{a}}$ & $9.769 \pm 1.4^{\mathrm{a}}$ & 500 & 81.169 & 51.18 & 71.286 \\
\hline Art & 0.045 & $0.039 \pm 0.0$ & - & - & - & - \\
\hline
\end{tabular}

P. falciparum strains: 3D7 chloroquine-sensitive, Dd2 chloroquine-resistant, and W2mef multi-drug resistant. LLC-MK2 cells: monkey kidney epithelial cells. $\mathrm{TC}_{\mathrm{MeOH}}$ and $\mathrm{TS}_{\mathrm{MeOH}}$ : methanol extracts of T. catappa and T. Superba, respectively. Art: artemether. SI: selectivity index.

a Same as on Table 2. - Not included in experimental scheme.

Substance with $\mathrm{CC}_{50}>30 \mu \mathrm{g} / \mathrm{mL}$ and $\mathrm{SI}>10$ are not cytotoxic (21).

In some parts of the South West region of Cameroon, the leaves of T. catappa is prepared as a decoction and used in the treatment of fever (5). Also several species of Terminalia are widely used for medicinal purposes to treat a broad spectrum of ailments including infectious diseases $(6,8)$. Crude extracts were prepared by maceration of portions of each plant powder separately in organic solvents of different polarities rather than sequentially in order to obtain crude extracts of different chemical composition to better appreciate their activity. This strategy permits identification of the extract(s) containing the most active constituent(s).

The crude extracts of both plants were largely active as shown in Tables 1 and 2 against both sensitive (3D7) and resistant strains (Dd2 and W2mef) of P. falciparum. Specifically, three extracts i.e. the methanol extracts of the two plants $\left(\mathrm{TC}_{\mathrm{MeOH}}\right.$ and $\mathrm{TS}_{\mathrm{MeOH}}$ ) and the methylene chloride extract of T. catappa $\left(\mathrm{TC}_{\mathrm{MC}}\right.$ ) were found to be active or moderately active on at least one of the three parasite strains according to one classification of antiplasmodial activity (22) (Table 2). The methanol extracts showed the highest antiplasmodial activity against all three parasite strains. The hexane extracts of both plants showed weak activity in the primary screen hence were not tested in the secondary screen. The trend of activity in the secondary screen was consistent with the primary screen for the methanol and methylene chloride extracts of both plants. This indicates the presence of more active constituents in the methanol extracts which are likely to be polar. Also, both plants and active extracts may have similar chemical composition since they are of the same genus. $\mathrm{TC}_{\mathrm{MeOH}}$ was however the most active extract on the resistant strains $\left(\mathrm{IC}_{50}\right.$ values $=5.03 \pm 0.16 \mu \mathrm{g} / \mathrm{mL}$ on $\mathrm{W} 2 \mathrm{mef}$ and $9.498 \pm$ $0.617 \mu \mathrm{g} / \mathrm{mL}$ on $\mathrm{Dd} 2)$. The $\mathrm{IC}_{50}$ values obtained for the methanol extract of T. catappa in this study are similar to those reported from previous studies on different parasite strains $(7.42 \pm 0.57 \mu \mathrm{g} / \mathrm{mL}$ on $P$. falciparum $\mathrm{K} 1$ and $9.4 \pm 1.08 \mu \mathrm{g} / \mathrm{mL}$ on NF54 (8); and $19.5 \mu \mathrm{g} / \mathrm{mL}$ on $P$. falciparum F32) (5). This study therefore further confirms the high antiplasmodial activity in T. catappa; and the consistency in the reported activity on several resistant strains of $P$. falciparum strongly indicates its potential for development into an antimalarial phytomedicine for treatment of resistant clinical malaria.

Phytochemical analyses of the leaves of T. catappa revealed the presence of alkaloids, flavonoids, resins, steroids, sugars, saponins, glycosides, phenols and ursolic acid $(7,8)$. Also, phytochemical analysis of T. superba revealed flavonoids, ellagic acid derivatives, phytosterols, triterpenoids, polyphenols and tannins (23). Some of these classes of compounds are known to inhibit P. falciparum, hence may be responsible for the high antiplasmodial activity of methanol extract $\left(\mathrm{TS}_{\mathrm{MeOH}}\right)$.

In the assessment of toxicity of active substances, a $\mathrm{CC}_{50}$ value $>30 \mu \mathrm{g} / \mathrm{mL}$ and $\mathrm{SI}>10$ were considered as cut points for lack of cytotoxicity and good selectivity, respectively (21). The most active crude extracts $\left(\mathrm{TC}_{\mathrm{MeOH}}\right.$ and $\left.\mathrm{TS}_{\mathrm{MeOH}}\right)$ fulfilled the criteria for lack of cytotoxicity with $\mathrm{CC}_{50}$ and SI values from $375 \mu \mathrm{g} / \mathrm{mL}$ and 40 , respectively (Table 3 ). This indicates a very low risk of toxicity which favours the
(A)

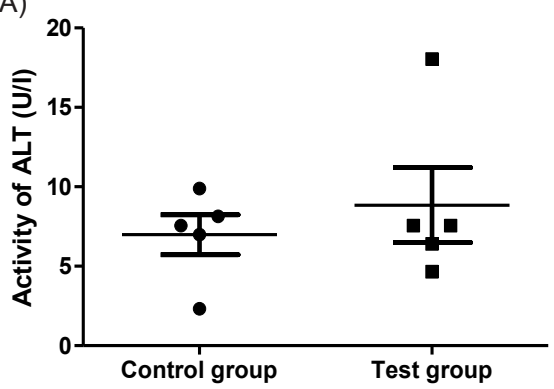

(B)

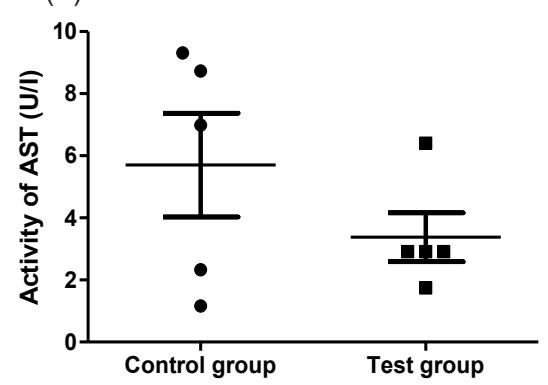

Figure 1. Effect of methanol extract of Terminalia catappa on mouse liver enzymes. A: ALT = Alanine aminotransferase $(P=0.50)$; $\mathrm{B}$ AST $=$ Aspartate aminotransferase $(P=0.24)$. 
use of the two plants for medicinal purposes.

Mbouna et al (12) recorded very high activity $\left(\mathrm{IC}_{50}=0.57\right.$ $\mu \mathrm{g} / \mathrm{mL}$ ) for the aqueous extract of T. superba leaves with very high SI of greater than 350 against resistant PfINDO; their $\mathrm{IC}_{50}$ of $3.38 \mathrm{IC}_{50} \mu \mathrm{g} / \mathrm{mL}$ and SI of 59 for the methanol extract are comparable to those of this study.

Furthermore, this study found that the active methanol extract of T. catappa had no significant effect $(P>0.2)$ on the liver enzymes in mice. ALT is found mainly in the liver whereas AST is present in the liver, heart and other organs; hence, elevation of ALT is more indicative of acute liver injury. The AST:ALT ratio for the test group (0.38) was much lower than that of the control group (0.82) suggesting ALT level was high in the test group. However, there was no significant difference in the ALT levels for the control and test groups $(P=0.506)$, suggesting no mild or acute hepatocellular damage on this vital organ which is the first to be exposed to a test substance following oral administration. Our findings agree with that of Ibegbulem et al (24), who recorded similar AST:ALT ratios for the control (0.85) and test groups (0.72) of Wistar rats administered a decoction of T. catappa orally.

\section{Conclusion}

The high antiplasmodial activity, high selectivity and lack of acute toxicity observed for Terminalia catappa supports its use in the traditional medicine. Development of the plant into an antimalarial phytomedicine should be pursued through in-depth studies in animal models including further toxicity tests in specific metabolic and organ systems.

\section{Acknowledgements}

The parasite strains were kindly donated by BEIResources, Manassas, Va, USA.

\section{Authors' contributions}

MNN conceived and designed the study, supervised the bench work and drafted the manuscript. DZ contributed to the study design, the bench work and performed the data analysis. JAM supervised the chemistry aspects of the work. GNA and TRK performed the bioassays. All authors read the manuscript, contributed in correcting it, and approved its final version.

\section{Conflict of Interests}

The authors declare that they have no conflict of interests.

\section{Ethical considerations}

Ethical issues (including plagiarism, misconduct, data fabrication, falsification, double publication or redundancy) have been completely considered by the authors. The animal study protocol was approved by the Institutional Animal Care and Use Committee, University of Buea (UB-IACUC No 013/2019).

\section{Funding/Support}

This work was sponsored by the University of Buea through funds provided to the Biotechnology Unit and also supported by a research grant awarded to Dr Denis Zofou by the International Foundation for Science (IFS)/ Organization for Prevention of Chemical Weapons (OPCW), Grant Number F/5122-1.

\section{References}

1. World Health Organization. Global Malaria Programme, 2018. In: Status report on Artemisinin resistance and artemisinin-based combination therapy efficacy. WHO/ CDS/GMP/2018.18. Accessed 27 December 2019.

2. Dondorp AM, Nosten F, Yi P, Das D, Phyo AP, Tarning J, et al. Artemisinin resistance in Plasmodium falciparum malaria. N Engl J Med. 2009;361(5):455-67. doi: 10.1056/ NEJMoa0808859.

3. World Health Organization (WHO). First Malaria Vaccine in Africa: A Potential New Tool for Child Health and Improved Malaria Control. WHO; 2019.

4. Rosenthal PJ. Antimalarial drug discovery: old and new approaches. J Exp Biol. 2003;206(Pt 21):3735-44. doi: 10.1242/jeb.00589.

5. Titanji VP, Zofou D, Ngemenya MN. The antimalarial potential of medicinal plants used for the treatment of malaria in Cameroonian folk medicine. Afr J Tradit Complement Altern Med. 2008;5(3):302-21.

6. Venkatalakshmi P, Vadivel V, Brindha P. Phtyopharmacological significance of Terminalia catappa L: an updated review. Int J Res Ayurveda Pharm. 2016;7(Suppl 2):130-7. doi: 10.7897/2277-4343.07272.

7. Mudi SY, Muhammad A. Antimalaria activity of ethanolic extracts of leaves of Terminalia catappa L. Combretaceae (Indian almond). Bayero J Pure Appl Sci. 2009;2(1):14-8. doi: 10.4314/bajopas.v2i1.58449.

8. Abiodun O, Gbotosho G, Ajaiyeoba E, Happi T, Falade $\mathrm{M}$, Wittlin $\mathrm{S}$, et al. In vitro antiplasmodial activity and toxicity assessment of some plants from Nigerian ethnomedicine. Pharm Biol. 2011;49(1):9-14. doi: 10.3109/13880209.2010.490224.

9. Mohd Abd Razak MR, Afzan A, Ali R, Amir Jalaluddin NF, Wasiman MI, Shiekh Zahari SH, et al. Effect of selected local medicinal plants on the asexual blood stage of chloroquine resistant Plasmodium falciparum. BMC Complement Altern Med. 2014;14:492. doi: 10.1186/1472-6882-14-492.

10. Kuete V, Tabopda TK, Ngameni B, Nana F, Tshikalange TE, Ngadjui BT. Antimycobacterial, antibacterial and antifungal activities of Terminalia superba (Combretaceae). S Afr J Bot. 2010;76(1):125-31. doi: 10.1016/j.sajb.2009.09.009.

11. Fahmy NM, Al-Sayed E, Singab AN. Genus Terminalia: a phytochemical and biological review. Med Aromat Plants. 2015;4(5):218. doi: 10.4172/2167-0412.1000218.

12. Mbouna CDJ, Kouipou RMT, Keumoe R, Tchokouaha LRY, Fokou PVT, Tali BMT, et al. Potent antiplasmodial extracts and fractions from Terminalia mantaly and Terminalia superba. Malar J. 2018;17(1):142. doi: 10.1186/s12936-0182298-1.

13. Anand AV, Divya N, Kotti PP. An updated review of Terminalia catappa. Pharmacogn Rev. 2015;9(18):93-8. doi: 
10.4103/0973-7847.162103.

14. Trager W, Jensen JB. Human malaria parasites in continuous culture. Science. 1976;193(4254):673-5. doi: 10.1126/ science.781840.

15. Moll K, Ljungström I, Perlmann H, Scherf A, Wahlgren M. Methods in Malaria Research. 6th ed. Manassas, Virginia: MR4/ATCC; 2013.

16. Desjardins RE, Canfield CJ, Haynes JD, Chulay JD. Quantitative assessment of antimalarial activity in vitro by a semiautomated microdilution technique. Antimicrob Agents Chemother. 1979;16(6):710-8. doi: 10.1128/ aac.16.6.710.

17. Zofou D, Tene M, Ngemenya MN, Tane P, Titanji VP. In vitro antiplasmodial activity and cytotoxicity of extracts of selected medicinal plants used by traditional healers of Western Cameroon. Malar Res Treat. 2011;2011:561342. doi: 10.4061/2011/561342.

18. Organisation for Economic Co-operation and Development (OECD). OECD Guidelines for Testing of Chemicals. Version 423 Adopted: 17 December 2001. Available from: http://www.oecd.org/chemicalsafety/testing/ oecdguidelinesforthetestingofchemicals.htm. Accessed 4 June 2017.

19. Ngemenya MN, Djeukem GGR, Nyongbela KD, Bate PNN,
Babiaka SB, Monya E, et al. Microbial, phytochemical, toxicity analyses and antibacterial activity against multidrug resistant bacteria of some traditional remedies sold in Buea Southwest Cameroon. BMC Complement Altern Med. 2019;19(1):150. doi: 10.1186/s12906-019-2563-Z.

20. Non linear evaluation of malaria drug sensitivity data (HNNonLin V1.1). Available from: http://www.meduniwien. ac.at/user/harald.noedl/malaria/software.html. Accessed 15 November 2019.

21. Malebo HM, Tanja W, Caletal M, Omolo MO, Hassanali A. Antiplasmodial, antitrypanosomal, antileshmanial and cytotoxicity activity of selected Tanzanian medicinal plants. Tanzan J Health Res. 2009;11(4):226-234.

22. Willcox M, Bodeker G, Rasoanaivo P. Traditional Medicinal Plants and Malaria. Paris: CRC Press; 2004. p. 12-35.

23. Dongmo AB, Beppe JG, Tsabang N, Kamanyi A. Analgesic activities of the stem bark extract of Terminalia superba Engl. Et Diels (Combreaaceae). Phamacologyonline. 2006;2:171-7.

24. Ibegbulem CO, Eyong EU, Essien EU. Biochemical effects of drinking Terminalia catappa Linn. decoction in Wistar rats. Afr J Biochem Res. 2011;5(8):237-43. doi: 10.5897/ ajbr. 9000045 . 